\title{
Roxithromycin compared with erythromycin against genitourinary chlamydial infections
}

\author{
ANNE-MARIE WORM,* GERDI HOFF, $\dagger$ SUSANNE KROON,* \\ CARSTEN SAND PETERSEN, * JENS JØRGEN CHRISTENSEN†
}

From the Departments of ${ }^{*}$ Dermatovenereology and $†$ Clinical Microbiology, Bispebjerg Hospital, Copenhagen, Denmark

SUMMARY The efficacy and safety of roxithromycin $300 \mathrm{mg}$ once a day was compared with that of erythromycin $500 \mathrm{mg}$ twice a day, both for seven days, in a double blind study of 281 patients (188 men, 93 women) with genitourinary chlamydial infections. At the end of the treatment $251(89 \%)$ patients were evaluable, and at follow up two weeks later $227(81 \%)$ were evaluable. The bacteriological cure rate was close to $100 \%$ at the end of both treatment regimens. At follow up 55/75 $(73 \%)$ evaluable men and $38 / 39(97 \%)$ evaluable women treated with roxithromycin were chlamydia negative compared with $50 / 71(70 \%)$ evaluable men and $37 / 42(88 \%)$ evaluable women treated with erythromycin. Of the 47 who were still chlamydia positive, reinfection could not be excluded in half the men and all the women.

Side effects were mainly gastrointestinal and were found in about $15 \%$ of patients receiving each treatment, but did not necessitate discontinuing treatment in any case. Roxithromycin seems to be as safe and efficacious as erythromycin in treating chlamydial infections in men and women, and it has the advantage that treatment is by a single daily dose.

Tetracycline and erythromycin are the drugs of choice in treating genitourinary chlamydial infections. The recommended periods of treatment and daily doses have varied in different studies from one to two weeks and from $1 \mathrm{~g}$ to $2 \mathrm{~g}$ divided into two, three, or even four daily doses.' Compliance of patients and thus the result of treatment depends, among other things, on the simplicity of the treatment. Roxithromycin is a new macrolide antibiotic with the same structure as erythromycin but a longer half life of about 10-12 hours, which indicates that this drug can be administered once a day. In vitro and in vivo studies have shown that roxithromycin is effective against Chlamydia trachomatis, ${ }^{23}$ and that it is safe, well tolerated, and well absorbed after administration by mouth. ${ }^{3}$ To evaluate this further, we compared treatment with roxithromycin $300 \mathrm{mg}$ a day with erythromycin $500 \mathrm{mg}$ twice a day, both for seven days, in men and women with uncomplicated genitourinary chlamydial infections.

Address for reprints: Dr A-M Worm, Department of Dermatovenereology, Bispebjerg Hospital, DK-2400 Copenhagen NV, Denmark

Accepted for publication 24 July 1988

\section{Patients, materials, and methods}

All men and women attending our outpatient venereal disease clinic are screened routinely for genitourinary chlamydial infections. We asked all patients who attended with uncomplicated chlamydial infections during a four month period to participate in the study. We excluded patients who had received antibiotics within the previous three days, who had concomitant gonococcal infection, a history of hypersensitivity to macrolide antibiotics, or severely impaired hepatic or renal function, and pregnant and nursing women.

We randomly assigned the patients to a double blind, double dummy, multiple dose trial, comparing roxithromycin $300 \mathrm{mg}$ once a day with erythromycin ethylsuccinate $500 \mathrm{mg}$ twice a day by mouth for seven days.

We asked the patients to return on days 8 and 21 after the start of treatment. Patients' complaints of urethral or vaginal discharge and pain were registered before entering the study and again at both follow up visits. Laboratory tests (haematology, liver and kidney function tests, and urine analysis) were performed before entering the study and again at the first follow up visit, at which time side effects were also listed.

We collected urethral and' cervical samples with 
cotton tipped aluminium swabs before the patients entered the study and at both follow up visits. $C$ trachomatis was identified by using cycloheximide treated McCoy cells ${ }^{4}$ followed by iodine staining and estimation of inclusion counts.

Sexual partners of the patients were encouraged to attend for examination, but were not treated epidemiologically.

The results were compared statistically by the $\chi^{2}$ test or Fisher's exact test.

\section{Results}

We enrolled 281 patients ( 188 men, 93 women) in the study. Of the men, $88 \%$ (166) were evaluable on day 8 and $78 \%(146)$ on day 21 . Of the women, $91 \%(85)$ were evaluable on day 8 and $87 \%$ (81) on day 21 (table). Evaluable patients were those who had taken the complete dose of the drug, returned for the follow up visits, and had not been treated with any other medication that could interfere with the results. Of those excluded, four men and one woman had concomitant gonococcal infection that had not been diagnosed at enrolment; the rest had not attended both follow up visits. None of the patients attending follow up had stopped taking the medication because of side effects. The patients in the two treatment groups were comparable for age, sex, and initial symptoms. More men treated with erythromycin than roxithromycin were lost to follow up, but the difference was not significant, whereas similar numbers of women were lost to follow up from the two treatment groups. At the start of treatment, symptoms compatible with genitourinary chlamydial infection were present in 147 (78\%) men and $47(51 \%)$ women. Symptoms in the men included discharge and urethral smears contain- ing more than five polymorphonuclear leucocytes per high power field ( $\times 1000$ magnification).

\section{Bacteriological efficacy}

The table shows the results at both follow up visits. Immediately after treatment (day 8) bacteriological cure was seen in $100 \%$ of men $(87 / 87)$ and women $(40 /$ 40 ) treated with roxithromycin and in $99 \%(78 / 79)$ of men and $100 \%(45 / 45)$ of women treated with erythromycin.

Two weeks after the end of treatment (day 21) $73 \%$ $(55 / 75)$ of the men treated with roxithromycin were chlamydia negative compared with $70 \%(50 / 71)$ of the men treated with erythromycin (not significant). Of the 41 men who were still chlamydia positive, half $(10 / 20)$ of those who received roxithromycin and $57 \%$ $(12 / 21)$ of those who received erythromycin said that reinfection was possible. The relapse rate in men might therefore have been as low as $15 \%$ in those treated with roxithromycin $(10 / 65)$ or with erythromycin $(9 / 59)$.

Two weeks after the end of treatment $97 \%(38 / 39)$ of the women treated with roxithromycin and $88 \%$ (37/42) of the women treated with erythromycin were chlamydia negative (not a significant difference). All women who were chlamydia positive at the last follow up visit had had sexual contact since the previous visit, so reinfection could not be excluded.

Roxithromycin and erythromycin thus had equal cure rates, but for both treatment regimens the cure rates were higher in women than in men, irrespective of the percentages of true relapses or reinfections.

\section{Clinical efficacy}

At the day 21 follow up visit the clinical efficacy rate in the 129 evaluable men who had had symptoms initially

Table Bacteriological response in 281 patients ( 188 men, 93 women) with genitourinary chlamydial infections treated with roxithromycin $300 \mathrm{mg}$ daily or erythromycin $500 \mathrm{mg}$ twice a day for seven days

\begin{tabular}{|c|c|c|c|c|}
\hline & \multicolumn{2}{|l|}{ Day 8 follow up } & \multicolumn{2}{|l|}{ Day 21 follow up } \\
\hline & $\begin{array}{l}\text { Roxithromycin } \\
(n=137)\end{array}$ & $\begin{array}{l}\text { Erythromycin } \\
(n=144)\end{array}$ & $\begin{array}{l}\text { Roxithromycin } \\
(n=137)\end{array}$ & $\begin{array}{l}\text { Erythromycin } \\
(n=144)\end{array}$ \\
\hline $\begin{array}{l}\text { Men: } \\
\text { Chlamydia negative } \\
\text { Chlamydia positive because of: } \\
\text { Relapse } \\
\text { Reinfection } \\
\text { Not evaluable }\end{array}$ & $\begin{array}{r}87 \\
0 \\
0 \\
0 \\
5\end{array}$ & $\begin{array}{r}78 \\
1 \\
1 \\
0 \\
17\end{array}$ & $\begin{array}{l}55 \\
20 \\
10 \\
10 \\
17\end{array}$ & $\begin{array}{r}50 \\
21 \\
9 \\
12 \\
25\end{array}$ \\
\hline Total & 92 & 96 & 92 & 96 \\
\hline $\begin{array}{l}\text { Women: } \\
\text { Chlamydia negative } \\
\text { Chlamydia positive because of: } \\
\text { Relapse } \\
\text { Reinfection } \\
\text { Not evaluable }\end{array}$ & $\begin{array}{r}40 \\
0 \\
0 \\
0 \\
5\end{array}$ & $\begin{array}{r}45 \\
0 \\
0 \\
0 \\
3\end{array}$ & $\begin{array}{r}38 \\
1 \\
0 \\
1 \\
6\end{array}$ & $\begin{array}{r}37 \\
5 \\
0 \\
5 \\
6\end{array}$ \\
\hline Total & 45 & 48 & 45 & 48 \\
\hline
\end{tabular}


was $84 \%(57 / 68)$ in those treated with roxithromycin and $82 \%(50 / 61)$ in those treated with erythromycin (not significant). Those who still had symptoms were all chlamydia positive because of reinfection or relapse.

At the day 21 follow up visit the clinical efficacy rate in the 42 evaluable women who had had symptoms initially was $95 \%(20 / 21)$ in those treated with roxithromycin and $86 \%(18 / 21)$ in those treated with erythromycin (not significant). Those who still had symptoms were all chlamydia positive, and reinfection could not be excluded.

\section{Side effects}

The most common side effects were gastrointestinal complaints including abdominal pain and nausea, which were recorded in $15 \%(21 / 137)$ of the patients receiving roxithromycin and $16 \%(23 / 144)$ of those receiving erythromycin. Other minor side effects, such as tiredness, headache, and slight itching, were registered equally often in $1 \%$ to $5 \%$ of patients receiving either treatment regimen. Vaginal candidiasis was found in two women, one treated with roxithromycin and one with erythromycin. Slight erythema was seen in two patients treated with erythromycin. None of the recorded side effects necessitated discontinuation of the treatment.

\section{Laboratory tests}

Two men, who had normal results before treatment and were both treated with erythromycin, showed increased liver function test results after treatment, one had a raised total bilirubin concentration only, and one had increased serum glutamic oxaloacetic transaminase (SGOT) and lactate dehydrogenase (LDH) activities. These patients had no known history of liver disease. None of the other patients tested showed any signs of haematological, renal, or hepatic toxicity during treatment.

\section{Discussion}

The recommended optimum daily doses and periods of treatment for eradicating genitourinary chlamydial infections differ between studies of patients treated with tetracycline or erythromycin. Treatments of choice according to the Centers for Disease Control are tetracycline $500 \mathrm{mg}$ four times a day for seven days or erythromycin $500 \mathrm{mg}$ four times a day for seven days for patients who cannot tolerate tetracycline and for pregnant women. ${ }^{5}$ Several studies have, however, shown that $1 \mathrm{~g}$ a day of tetracycline ${ }^{6-8}$ or erythromycin $^{68-10}$ for seven days ${ }^{679}$ or 14 days $^{8-10}$ have had satisfactory effects. Shorter durations of treatment have not been recommended. ${ }^{.1-13}$

Erythromycin given in doses of $2 \mathrm{~g}$ a day has a high incidence of gastrointestinal side effects that decreases compliance and makes more patients discontinue the treatment. ${ }^{14}$ There therefore seems to be a need for further studies elucidating the effect of other macrolides in genitourinary chlamydial infections. In this study we found that roxithromycin $300 \mathrm{mg}$ once a day and erythromycin $500 \mathrm{mg}$ twice a day, given orally for seven days, had similar effects. Gastrointestinal side effects were recorded in about $15 \%$ of the patients irrespective of the treatment, but not to a degree that caused any of the patients evaluable to discontinue the treatment. That less frequent administration of treatment is an important advantage in patient compliance has been shown in a study comparing treatment with doxycycline with tetracycline in patients with gonococcal infections. ${ }^{15}$ Roxithromycin should therefore be preferable to erythromycin when treating patients with chlamydial infections.

Some studies have found that more women than men with chlamydial infections are cured when given the same treatment, ${ }^{114}$ a difference that might be related to lower serum concentrations in patients with greater body weights. ${ }^{14}$ The same trend was also found in this study, with higher cure rates in women than men in both treatment groups. The cure rates in different studies are difficult to compare because of differences in duration of follow up and whether sexual partners are treated epidemiologically. In this study half the men and all the women still chlamydia positive when evaluated two weeks after the end of the treatment might have been reinfected, which gave a cure rate for roxithromycin of $74 \%$ to $87 \%$ in men and $97 \%$ to $100 \%$ in women. The corresponding cure rate for erythromycin was $71 \%$ to $87 \%$ in men and $88 \%$ to $100 \%$ in women. We therefore conclude that roxithromycin seems to be a safe and effective alternative treatment for genitourinary chlamydial infections, and has the advantage of being administered as a single daily dose.

We thank Roussel-Uclaf for the supply of the treatment drugs.

\section{References}

1 Stamm WE, Holmes KK. Chlamydia trachomatis infection of the adult. In: Holmes KK, Mårdh P-A, Sparling PF, Wiesner PJ, eds. Sexually transmitted diseases. New York: McGraw Hill, 1984:258-70.

2 Bowie W, Shaw CE, Chan DGW, Black WA. In vitro activity of Ro 15-8074, Ro 19-5247, A-56268, and roxithromycin (RU 28965) against Neisseria gonorrhoeae and Chlamydia trachomatis. Antimicrob Agents Chemother 1987;31:470-2.

3 van der Willigen AH, Tjiam KH, Wagenvoort JHT, PolakVogelzang AA, Michel MF, Stolz E. Evaluation of roxithromycin in the treatment of non-gonococcal urethritis in males. Eur J Clin Microbiol 1986;5:612-4.

4 Ripa KT, Mårdh P-A. New simplified culture technique for 
chlamydia trachomatis. In: Hobson D, Holmes KK, eds. Nongonococcal urethritis and related infections. Washington DC: American Society for Microbiology, 1977:323-7.

5 Sanders LL, Harrison HR, Washington AE. Treatment of sexually transmitted chlamydial infections. JAMA 1986;255:1750-6.

6 Scheibel JH, Kristensen JK, Hentzer B, et al. Treatment of chlamydial urethritis in men and Chlamydia trachomatispositive female partners: comparison of erythromycin and tetracycline in treatment courses of one week. Sex Transm Dis 1982;9:128-31.

7 Darne JF, Ridgway GL, Oriel JD. Rosaramicin and tetracycline in the treatment of non-gonococcal urethritis. British Journal of Venereal Diseases 1982;58:117-20.

8 Oriel JD, Ridgway GL. Comparison of erythromycin and oxytetracycline in the treatment of cervical infection by Chlamydia trachomatis. J Infect 1980;2:259-62.

9 Hunter JM, Sommerville RG. Erythromycin stearate in treating chlamydial infection of the cervix. British Journal of Venereal Diseases 1984;60:387-9.

10 Oriel JD, Ridgway GL, Tchamouroff S. Comparison of erythro- mycin stearate and oxytetracycline in the treatment of nongonococcal urethritis. Scot Med J 1977;22:375-9.

11 Worm AM, Avnstorp C, Petersen CS. Erythromycin against Chlamydia trachomatis infections. Dan Med Bull 1985;32 269-71.

12 Csángó PA, Salveson A, Gundersen T, Jagars G, Bjerk O. Treatment of acute gonococcal urethritis in men with simultaneous infection with Chlamydia trachomatis. British Journal of Venereal Diseases 1984;60:95-8.

13 Stamm WE, Guinan ME, Johnson C, Starcher T, Holmes KK, McCormack WM. Effect of treatment regimens for Neisseria gonorrhoeae on simultaneous infection with Chlamydia trachomatis. N Engl J Med 1984;310:545-9.

14 Linnemann CC, Heaton CL, Ritchey M. Treatment of Chlamydia trachomatis infections: comparison of $1-$ and 2-g doses of erythromycin daily for seven days. Sex Transm Dis 1986;14:102-6.

15 Jordan WC. Doxyline vs tetracycline in the treatment of men with gonorrhea. The compliance factor. Sex Transm Dis 1981;8 suppl:105-9. 